RESEARCH REPORT

\title{
Primary care, infant mortality, and low birth weight in the states of the USA
}

\author{
L Shi, J Macinko, B Starfield, J Xu, J Regan, R Politzer, J Wulu
}

J Epidemiol Community Health 2004;58:374-380. doi: 10.1136/jech.2003.013078

See end of article for authors' affiliations

.....................

Correspondence to: L Shi, Department of Health Policy and Management, Johns Hopkins Bloomberg School of Public Health, $624 \mathrm{~N}$ Broadway, Room 406, Baltimore, 21205, USA; Ishi@jhsph.edu

Accepted for publication 19 October 2003

\begin{abstract}
Study objective: The study tests the extent to which primary care physician supply (office based primary care physicians per 10000 population) moderates the association between social inequalities and infant mortality and low birth weight throughout the 50 states of the USA.

Design: Pooled cross sectional, time series analysis of secondary data. Analyses controlled for state level education, unemployment, racial/ethnic composition, income inequality, and urban/rural differences. Contemporaneous and time lagged covariates were modelled.

Setting: Eleven years (1985-95) of data from 50 US states (final $n=549$ because of one missing data point).

Main results: Primary care was negatively associated with infant mortality and low birth weight in all multivariate models $(p<0.0001)$. The association was consistent in contemporaneous and time lagged models. Although income inequality was positively associated with low birth weight and infant mortality $(p<0.0001)$, the association with infant mortality disappeared with the addition of sociodemographic covariates.

Conclusions: In US states, an increased supply of primary care practitioners - especially in areas with high levels of social disparities - is negatively associated with infant mortality and low birth weight.
\end{abstract}

$\mathrm{T}$ here is considerable evidence of an association between social inequalities and health outcomes within the United States. ${ }^{1-5}$ In general, these studies have found that a greater gap in income distribution between the rich and poor in a given geographical area is associated with poorer population health in that area.

There are several competing theories as to why social inequalities should be related to health. Psychosocial theories hold that disparities in social standing (often measured by income or occupation) create stresses that can eventually damage a person's health..$^{6-9}$ Social capital explanations hold that individual and group level social relationships influence population health either directly or through more proximal factors. One hypothesis is that more egalitarian areas are more socially cohesive, leading to greater levels of trust and cooperation, less psychosocial stress, and, consequently, better health status. ${ }^{10}{ }^{11}$ Other investigators have suggested that geographical areas with greater social inequalities may suffer from systematic underinvestment in schooling, health care, and housing, and that these "neo-material" factors consequently lead to poorer health status among the disadvantaged. ${ }^{12-14}$ Finally, others have suggested that it is ultimately the political and policy context of a political unit that allows social and material disparities to develop and, to lead to persistent health inequalities among the most socially disadvantaged..$^{15} 16$

Our previous published studies showed that primary care might mitigate the adverse associations of social inequalities on adult health in the United States. ${ }^{17}{ }^{18}$ Using 1990 US state level data, we found a significant association between primary care physician supply and reduced all cause and cause specific mortality and increased life expectancy, even after controlling for income inequality and population sociodemographic characteristics. Similar findings were noted using US metropolitan areas as the unit of analysis ${ }^{18}$ and in mixed level analyses. ${ }^{19}{ }^{20}$ Although different units of analyses (that is, state, metropolitan, and individual) show fairly consistent findings, these studies were limited by their cross sectional design.
This study investigates these limitations by using 11 years of US state level data to examine the impact of primary care on both infant mortality and prevalence of low birth weight within areas of high social inequalities. An independent association of primary care on these health outcomes implies that improvements in primary care can lead to improved health outcomes, independent of social inequalities. This is particularly relevant in the United States, where health inequalities among population groups continue to increase despite of national commitments to reduce them. ${ }^{21}$

\section{METHODS}

\section{Data and measures}

The first dependent variable, average state infant mortality rate (IMR), is expressed as the number of deaths of infants under 1 year of age per 1000 live births during the same year and was calculated using the Compressed Mortality Files. ${ }^{22}$ The other dependent variable, low birth weight (LBW) is defined as the percentage of all live births in which the infant weighed $<2500 \mathrm{~g}$ and was calculated using data from the National Center for Health Statistics. ${ }^{23}$

Primary care is measured using the number of office based primary care physicians per 10000 population in each state. The term "primary care physicians" refers to doctors of medicine working in family medicine, general practice, internal medicine, and paediatrics who were in active office based patient care. ${ }^{24}$ Although in the United States obstetrician-gynaecologists sometimes serve as women's primary care providers, they are trained primarily as specialists, not as primary care providers. For this reason, they were not included in the primary care measure. Physician data were obtained from the American Medical Association annual publication, Physician Characteristics and Distribution in the United States ${ }^{25}$

Abbreviations: LBW, low birth weight; IMR, infant mortality rate; LRT, likelihood ratio test 
Income distribution was measured by the Gini coefficient, a commonly used indicator of income inequality wherein higher values indicate greater inequality in income distribution. The Gini coefficient was calculated using software developed by Ed Welniak (unpublished software, US Census Bureau, 1988) using data from the US Census Bureau. We did not construct other measures of income inequality because prior studies using similar data indicated that the choice of income distribution measure did not seem to affect results. ${ }^{26}$

Additional sociodemographic variables known to be associated with population health were included in the analyses as covariates. They included the proportion of each state's population aged 25 that had completed at least 12 years of formal education (Education), the proportion of the state work force population currently unemployed (Unemployed), the proportion of state population whose race is identified as African-American (African-American), and the proportion of each state's population that resides in urban rather than rural areas (Metro). These data were obtained from the Statistical Abstracts of the United States. ${ }^{27}$ Other covariates, such as income per capita, were not included in the model because of potential collinearity with the income inequality measure. ${ }^{28}$ Instead, socioeconomic status is represented in the model by levels of education.

All data were drawn from 1985 to 1995. This period represents the latest dates for which all data were available.

\section{Design}

This study was a longitudinal ecological analysis of the unmixed type-that is, our analyses correlated ecological variables with ecological outcomes. ${ }^{29}$ We avoided cross level bias by making no inferences about individuals from grouped data. ${ }^{30}$ The unit of analysis was each of the 50 US states for the 11 year period 1985-1995. One data point (Delaware in 1991) was dropped because of missing values $(n=549$ instead of 550). Washington, DC was not included in the analysis because it is not a state. One advantage of using states as the unit of analysis is the lower likelihood of random fluctuations in mortality and other rates at levels of smaller geographical aggregation. Using state level aggregate data also had the advantage of attenuating the probable "cross over" association encountered when patients travel outside their local geographical area to obtain health care. ${ }^{31}$

\section{Analysis}

We analysed the intercorrelations between primary care, income inequality, sociodemographic covariates, and mortality using Pearson's correlation coefficients. For longitudinal analyses, we used a pooled, cross sectional, time series design. This design analyses a cross section of units of observation (states) over a span of time (years). Ordinary least squares (OLS) regression will not yield proper estimates on data containing repeated measures. For this reason, parameters were estimated using the SAS PROC MIXED procedure. $^{32}$ This approach uses a maximum likelihood estimator to account for correlation among error terms due to the presence of repeated measures (each year) on the same unit (state). Moreover, this procedure provides estimates for both fixed and time varying covariates, and models not only the means of the data but also the variances and covariances. $^{33}$ In the model, all outcomes were treated as continuous. States were treated as fixed effects, thus allowing the model to control for comparatively stable inter-state differences, such as policy context and historical differences in technology, resources, and other determinants of population health. ${ }^{34}$

In the regression analyses a set of nested models was designed to examine the extent to which primary care moderates the association between income inequality and infant mortality and LBW. In bivariate analyses (model 1), only income inequality was used as a predictor of the outcome. A second model (model 2) examines the same relation while adjusting for primary care. A third and final model (model 3) examines income inequality, primary care, and sociodemographic characteristics of the state. Regression coefficients are presented along with tests of significance. Changes in the regression coefficients of income inequality across models reflect the extent primary care and sociodemographic characteristics moderate the association between income inequality and infant mortality. Nested models are compared (that is, model 3 versus model 2; model 2 versus model 1) by calculating the likelihood ratio test (LRT). This allows us to determine whether the additional covariates in each model are significantly different from zero. ${ }^{35}$ An interaction term (primary care $\times$ Gini) is used to examine if primary care influences health at different levels of income inequality.

As the associations of the predictors on health outcomes are expected to materialise over time, we also conducted longitudinal analyses with time lags. A total of three time lag models (one, three, and five years) were modelled. A one year lag model shows the outcomes as a function of the independent measures of the previous year. A three year lag model shows the outcomes as a function of the independent measures from three years before, and likewise. The time lag models are meant to portray the relations between the measures and identify when the most significant latent association occurs.

\section{RESULTS}

Between 1985 and 1995, there was a steady increase in LBW in the United States, from about $6.6 \%$ to $7.1 \%$ of live births (fig 1). In the same period, there was a pronounced decline in infant mortality. The mean state infant mortality rate dropped about 29\%, from nearly 10.5 in 1985 to about 7.5 per 1000 in 1995 (fig 1). Primary care physicians increased from 5.02 to 6.04 per 10000 population (fig 1). Income inequality within states fluctuated during the period with an overall worsening trend; the mean of the Gini coefficient among states increased from 0.41 to 0.43 during the period.

Table 1 presents the correlation matrix (1985-1995) among dependent and independent variables used in this study. The table shows that primary care was negatively and significantly associated with both infant mortality $(p<0.05)$ and LBW $(p<0.01)$. Income inequality was positively associated

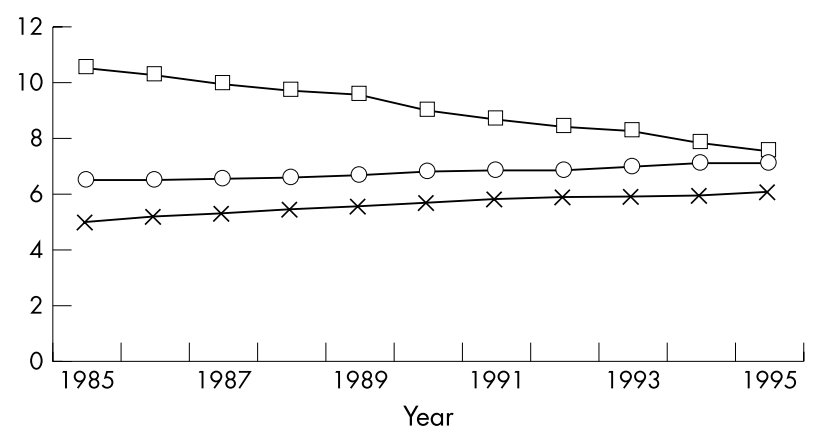


Table 1 Pearson correlation matrix of state level infant mortality, low birth weight, income inequality, primary care, and sociodemographic indicators, 1985-1995†

\begin{tabular}{|c|c|c|c|c|c|c|c|c|}
\hline$n=549$ & $\begin{array}{l}\text { Low birth } \\
\text { weight }\end{array}$ & $\begin{array}{l}\text { Infant mortality } \\
\text { rate }\end{array}$ & Gini & Primary care & $\begin{array}{l}\text { African- } \\
\text { American }\end{array}$ & Metro & Unemployed & Education \\
\hline $\begin{array}{l}\text { Low birth weight } \\
\text { Infant mortality per } \\
1000 \text { live births (infant) }\end{array}$ & $\begin{array}{l}1.00 \\
0.56 \text { to } 0.77^{* *}\end{array}$ & 1.00 & & & & & & \\
\hline Gini coefficient (Gini) & 0.32 to 0.65 & 0.14 to 0.50 & 1.00 & & & & & \\
\hline $\begin{array}{l}\text { Office based patient } \\
\text { primary care doctor ratio } \\
\text { (primary care supply) }\end{array}$ & $\begin{array}{l}-0.28 \text { to } \\
-0.45^{*}\end{array}$ & $\begin{array}{l}-0.32 \text { to } \\
-0.53^{\star *}\end{array}$ & $\begin{array}{l}-0.01 \text { to } \\
0.11\end{array}$ & 1.00 & & & & \\
\hline $\begin{array}{l}\text { Proportion (\%) African-American } \\
\text { (African-American) }\end{array}$ & 0.81 to $0.87^{* *}$ & 0.70 to $0.83^{* *}$ & 0.28 to 0.69 & $\begin{array}{l}-0.16 \text { to } \\
-0.38\end{array}$ & 1.00 & & & \\
\hline $\begin{array}{l}\text { Proportion (\%) of metropolitan } \\
\text { population (Metro) }\end{array}$ & 0.17 to 0.31 & $\begin{array}{l}-0.02 \text { to } \\
-0.08\end{array}$ & 0.01 to 0.43 & 0.24 to 0.35 & 0.21 to 0.29 & 1.00 & & \\
\hline $\begin{array}{l}\text { Proportion (\%) of unemployed } \\
\text { population (unemployed) }\end{array}$ & 0.19 to 0.35 & -0.10 to 0.35 & 0.15 to 0.60 & $\begin{array}{l}-0.03 \text { to } \\
-0.51\end{array}$ & 0.17 to 0.26 & $\begin{array}{l}-0.05 \text { to } \\
0.33\end{array}$ & 1.00 & \\
\hline $\begin{array}{l}\% \text { Population } \geqslant 25 \text { years } \\
\text { and completed } 12 \text { years of } \\
\text { education (education) }\end{array}$ & $\begin{array}{l}-0.60 \text { to } \\
-0.70^{* *}\end{array}$ & $\begin{array}{l}-0.52 \text { to } \\
-0.67^{* \star}\end{array}$ & $\begin{array}{l}-0.37 \text { to } \\
-0.66^{* *}\end{array}$ & 0.27 to 0.47 & $\begin{array}{l}-0.67 \text { to } \\
-0.70^{* *}\end{array}$ & 0.03 to 0.07 & $\begin{array}{l}-0.16 \text { to } \\
-0.43\end{array}$ & 1.00 \\
\hline Mean & 6.6 to 7.1 & 755 to 1057 & 0.40 to 0.43 & 5.02 to 6.04 & 0.09 to 0.10 & 63.4 to 67.0 & 5.2 to 7.1 & $\begin{array}{l}67.5 \text { to } \\
78.5\end{array}$ \\
\hline
\end{tabular}

tRange (lowest to highest) of correlation from 1985 to 1995. The correlation was considered statistically significant only if every year's correlation coefficient was statistically significant, otherwise, no asterisk labelled. The bottom row is the range of means for each predictor from 1985 to 1995 . ${ }^{*}<0.05$; ${ }^{* *} 0.01$. Sources, see references. ${ }^{22-25} 27$

with both infant mortality and LBW, but because of the fluctuations in Gini over time, these relations were not statistically significant for each year. Among sociodemographic indicators, the percentage of the state population identified as African-American was highly correlated with both health outcomes $(\mathrm{p}<0.01)$, while the proportion of the state population with at least a high school education was negatively associated with both outcomes $(\mathrm{p}<0.01)$.

Table 2 presents results of the pooled, cross sectional, time series regression model examining predictors of state level LBW. In bivariate analyses (model 1), contemporaneous measures of income inequality were significantly associated with higher state levels of LBW $(\mathrm{p}<0.0001)$. In analyses additionally adjusting for primary care (model 2 ), primary care was significantly associated with lower LBW $(\mathrm{p}<0.0001)$ and income inequality remained the same as in bivariate analyses. With the addition of sociodemographic covariates (model 3), primary care decreased in magnitude by one half but remained a significant $(\mathrm{p}<0.0001)$ predictor of lower LBW. In this model, the coefficient for income inequality decreased to about one sixth of its value in the bivariate analyses, but also remained significant $(p<0.01)$. The proportion of the state's population that is AfricanAmerican was associated with higher LBW $(p<0.0001)$, while the percentage urban and the percentage with at least a high school education were both associated with lower LBW $(\mathrm{p}<0.0001$ and $\mathrm{p}<0.001$, respectively).

The overall pattern seen in the contemporaneous model persisted in the time lagged models. Primary care was a statistically significant predictor of lower LBW, and the magnitude of this relation was stable over time. The association with race/ethnicity, urban residence and education also persisted in the time lagged models. Income inequality was an exception. The magnitude of the

Table 2 Contemporary and lagged pooled, cross sectional time series analyses of predicted low birth weight births as percentage of all births, US states, 1985-1995

\begin{tabular}{|c|c|c|c|c|c|c|c|c|c|c|c|c|}
\hline \multirow[b]{2}{*}{ Model } & \multicolumn{3}{|c|}{ Same yeart } & \multicolumn{3}{|c|}{ One year lagt } & \multicolumn{3}{|c|}{ Three year lagt } & \multicolumn{3}{|c|}{ Five year lagt } \\
\hline & 1 & 2 & 3 & 1 & 2 & 3 & 1 & 2 & 3 & 1 & 2 & 3 \\
\hline Intercept & $\begin{array}{l}-0.8 \\
(0.6)\end{array}$ & $\begin{array}{l}1.3 \\
(0.7)\end{array}$ & $\begin{array}{l}6.3 \\
(0.7)\end{array}$ & $\begin{array}{l}-0.8 \\
(0.7)\end{array}$ & $\begin{array}{l}1.6 \\
(0.8)\end{array}$ & $\begin{array}{l}6.6 \\
(0.7)\end{array}$ & $\begin{array}{l}-0.9 \\
(0.8)\end{array}$ & $\begin{array}{l}2.1 \\
(0.9)\end{array}$ & $\begin{array}{l}6.5 \\
(0.8)\end{array}$ & $\begin{array}{l}-0.6 \\
(0.8)\end{array}$ & $\begin{array}{l}2.8 \\
(1.0)\end{array}$ & $\begin{array}{l}6.7 \\
(0.8)\end{array}$ \\
\hline Gini coefficient & $\begin{array}{l}18.3^{* \star \star *} \\
(1.5)\end{array}$ & $\begin{array}{l}18.2^{* * * *} \\
(1.5)\end{array}$ & $\begin{array}{l}3.0^{* *} \\
(1.1)\end{array}$ & $\begin{array}{l}18.4^{* * * *} \\
(1.6)\end{array}$ & $\begin{array}{l}17.8^{* * * *} \\
(1.6)\end{array}$ & $\begin{array}{l}2.1 \\
(1.2)\end{array}$ & $\begin{array}{l}18.8^{* * * *} \\
(1.9)\end{array}$ & $\begin{array}{l}17.4^{* * * *} \\
(1.8)\end{array}$ & $\begin{array}{l}2.2 \\
(1.3)\end{array}$ & $\begin{array}{l}18.2^{* \star \star *} \\
(2.0)\end{array}$ & $\begin{array}{l}16.9^{* * * *} \\
(1.9)\end{array}$ & $\begin{array}{l}2.7^{*} \\
(1.4)\end{array}$ \\
\hline Primary care supply & & $\begin{array}{l}-0.4^{\star * * *} \\
(0.05)\end{array}$ & $\begin{array}{l}-0.2^{\star \star \star *} \\
(0.03)\end{array}$ & & $\begin{array}{l}-0.4^{* * * *} \\
(0.1)\end{array}$ & $\begin{array}{l}-0.2^{* * * *} \\
(0.04)\end{array}$ & & $\begin{array}{l}-0.4^{* * * *} \\
(0.1)\end{array}$ & $\begin{array}{l}-0.2^{* * * *} \\
(0.04)\end{array}$ & & $\begin{array}{l}-0.5^{\text {}}(0.1) \\
(0 . *\end{array}$ & $\begin{array}{l}-0.2^{\star * \star} \\
(0.1)\end{array}$ \\
\hline$\%$ African-American§ & & & $\begin{array}{l}8.9^{* \star \star *} \\
(0.4)\end{array}$ & & & $\begin{array}{l}9.1^{* \star \star \star} \\
(0.4)\end{array}$ & & & $\begin{array}{l}9.4^{* \star * \star} \\
(0.5)\end{array}$ & & & $\begin{array}{l}9.1^{1 * \star *} \\
(0.6)\end{array}$ \\
\hline$\%$ Metro & & & $\begin{array}{l}-0.01^{* * * *} \\
(0.001)\end{array}$ & & & $\begin{array}{l}-0.01^{\star * \star *} \\
(0.001)\end{array}$ & & & $\begin{array}{l}-0.01^{\star * *} \\
(0.002)\end{array}$ & & & $\begin{array}{l}-0.01^{\star *} \\
(0.002)\end{array}$ \\
\hline Unemployment†† & & & $\begin{array}{l}-0.02 \\
(0.02)\end{array}$ & & & $\begin{array}{l}0.03 \\
(0.02)\end{array}$ & & & $\begin{array}{l}0.04^{*} \\
(0.02)\end{array}$ & & & $\begin{array}{l}0.05^{*} \\
(0.02)\end{array}$ \\
\hline Education $\ddagger \ddagger$ & & & $\begin{array}{l}-0.02^{* *} \\
(0.01)\end{array}$ & & & $\begin{array}{l}-0.02^{* *} \\
(0.01)\end{array}$ & & & ${ }^{-0.01}{ }^{*}$ & & & $\begin{array}{l}-0.02^{* *} \\
(0.01)\end{array}$ \\
\hline$-2 \mathrm{LL}$ & 1633.0 & 1589.7 & 1068.3 & 1496.1 & 1454.0 & 979.2 & 1209.0 & 1172.5 & 779.6 & 908.3 & 869.0 & 584.2 \\
\hline$\Delta d f \S \S$ & - & 1 & 4 & - & 1 & 4 & - & 1 & 4 & - & 1 & 4 \\
\hline$\Delta \mathrm{chsq}$ & - & 43.3 & 521.4 & - & 42.1 & 474.8 & - & 36.5 & 392.9 & - & 39.3 & 284.8 \\
\hline LRT††† & - & $43.3^{* *}$ & $130.4^{* *}$ & - & $42.1^{\text {** }}$ & $118.7^{* *}$ & - & $36.5^{\text {** }}$ & $98.2^{* *}$ & - & $39.3^{\text {** }}$ & $71.2^{* *}$ \\
\hline
\end{tabular}

${ }^{*} 0.01<p<0.05 ;{ }^{* *} 0.001<p<0.01 ;{ }^{* * *} 0.0001<p<0.001 ;{ }^{* * * *} p<0.0001$. tEstimated coefficient and standard errors (in parentheses) were provided from mixed models. Time lagged models predict contemporary dependent variables using one, three, or five year lagged covariates. $\neq$ Primary care physicians per 10000 population. §Percentage state population that is African-American. - Percentage state population in metropolitan areas. ††Percentage of state population unemployed.

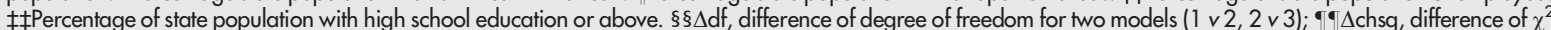
for two models ( $1 \vee 2,2 \vee 3$ ); ††+LRT (likelihood ratio test), ( $\Delta$ of $\chi^{2}$ for two models)/( $\Delta$ of df for two models). Sources, see references. ${ }^{22-25} 27$ 
Table 3 Contemporary and lagged pooled, cross sectional time series analyses of predicted, infant mortality per 1000 live births, US states, 1985-1995

\begin{tabular}{|c|c|c|c|c|c|c|c|c|c|c|c|c|}
\hline \multirow[b]{2}{*}{ Model } & \multicolumn{3}{|c|}{ Same yeart } & \multicolumn{3}{|c|}{ One year lagt } & \multicolumn{3}{|c|}{ Three year lagt } & \multicolumn{3}{|c|}{ Five year lagt } \\
\hline & 1 & 2 & 3 & 1 & 2 & 3 & 1 & 2 & 3 & 1 & 2 & 3 \\
\hline Intercept & $\begin{array}{l}216.6 \\
(89.9)\end{array}$ & $\begin{array}{l}654.7 \\
(90.8)\end{array}$ & $\begin{array}{l}1027 \\
(100.7)\end{array}$ & $\begin{array}{l}211.1 \\
(92.0)\end{array}$ & $\begin{array}{l}673.6 \\
(94.1)\end{array}$ & $\begin{array}{l}1098 \\
(102.0)\end{array}$ & $\begin{array}{l}159.8 \\
(97.0)\end{array}$ & $\begin{array}{l}671.1 \\
(102.4)\end{array}$ & $\begin{array}{l}1122 \\
(107.2)\end{array}$ & $\begin{array}{l}84.7 \\
(102.1)\end{array}$ & $\begin{array}{l}611.6 \\
(109.4)\end{array}$ & $\begin{array}{l}965.5 \\
(108.3)\end{array}$ \\
\hline Gini coefficient & $\begin{array}{l}1663^{* * * *} \\
(199.2)\end{array}$ & $\begin{array}{l}1469^{* * * *} \\
(183.2)\end{array}$ & $\begin{array}{l}92.2 \\
(152.4)\end{array}$ & $\begin{array}{l}1647^{* * * *} \\
(206.4)\end{array}$ & $\begin{array}{l}1410^{* * * *} \\
(189.7)\end{array}$ & $\begin{array}{l}-51.4 \\
(158.1)\end{array}$ & $\begin{array}{l}1712^{* \star * *} \\
(224.3)\end{array}$ & $\begin{array}{l}1400^{* * * *} \\
(206.5)\end{array}$ & $\begin{array}{l}-91.8 \\
(170.7)\end{array}$ & $\begin{array}{l}1813^{* * * *} \\
(238.6)\end{array}$ & $\begin{array}{l}1492^{* * \star *} \\
(218.2)\end{array}$ & $\begin{array}{l}32.5 \\
(179.7)\end{array}$ \\
\hline Primary care supply $\ddagger$ & & $\begin{array}{l}-63.6^{* * \star *} \\
(6.1)\end{array}$ & $\begin{array}{l}-25.2^{\star \star * \star} \\
(4.8)\end{array}$ & & $\begin{array}{l}-65.4^{* \star * \star} \\
(6.4)\end{array}$ & $\begin{array}{l}{ }^{*}-25.4^{* \star * *} \\
(5.1)\end{array}$ & & $\begin{array}{l}-69.7^{* * * *} \\
(7.4)\end{array}$ & $\begin{array}{l}-27.0^{* \star * *} \\
(6.0)\end{array}$ & & $\begin{array}{l}-73.6^{* * * *} \\
(8.7)\end{array}$ & $\begin{array}{l}-19.2^{* *} \\
(7.3)\end{array}$ \\
\hline$\%$ African-American§ & & & $\begin{array}{l}1117^{* * * *} \\
(56.5)\end{array}$ & & & $\begin{array}{l}1100^{* * * *} \\
(59.2)\end{array}$ & & & $\begin{array}{l}1047^{* * \star *} \\
(66.8)\end{array}$ & & & $\begin{array}{l}994.6^{* \star * *} \\
(75.4)\end{array}$ \\
\hline \% Metro & & & $\begin{array}{l}-1.1^{* \star * \star} \\
(0.2)\end{array}$ & & & $\begin{array}{l}-1.1^{* * * *} \\
(0.2)\end{array}$ & & & $\begin{array}{l}-0.9^{* * * * *} \\
(0.2)\end{array}$ & & & $\begin{array}{l}-1.0^{\star \star \star \star \star} \\
(0.2)\end{array}$ \\
\hline Unemploymentt† & & & $\begin{array}{l}-1.2 \\
(2.3)\end{array}$ & & & $\begin{array}{l}-0.3 \\
(2.3)\end{array}$ & & & $\begin{array}{l}2.5 \\
(2.5)\end{array}$ & & & $\begin{array}{l}8.9^{* *} \\
(2.9)\end{array}$ \\
\hline Education $¥ \ddagger$ & & & $\begin{array}{l}-0.6 \\
(0.8)\end{array}$ & & & $\begin{array}{l}-1.0 \\
(0.8)\end{array}$ & & & $\begin{array}{l}-1.8^{*} \\
(0.9)\end{array}$ & & & $\begin{array}{l}-1.9^{*} \\
(0.9)\end{array}$ \\
\hline$-2 L \mathrm{~L}$ & 6927.2 & 6821.5 & 6392.2 & 6287.0 & 6187.8 & 5796.9 & 5017.1 & 4932.4 & 4623.6 & 3742.2 & 3672.2 & 3437.0 \\
\hline$\Delta \mathrm{df} \S \S$ & - & & 4 & - & & 4 & - & & 4 & - & & 4 \\
\hline$\Delta$ chsq & - & 105.7 & 429.3 & - & 99.2 & 390.9 & - & 84.7 & 308.8 & - & 70.0 & 235.2 \\
\hline LRTTtT & - & $105.7^{* *}$ & $107.3^{* *}$ & - & $99.2^{\star *}$ & $97.7^{* *}$ & - & $84.7^{\star *}$ & $77.2^{\star *}$ & - & $70.0^{* *}$ & $58.8^{* *}$ \\
\hline \multicolumn{13}{|c|}{ 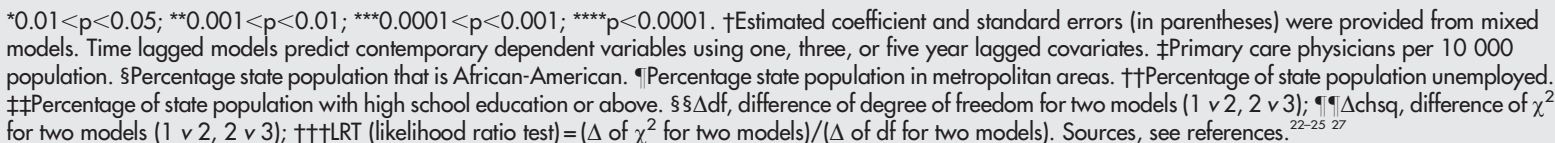 } \\
\hline
\end{tabular}

association between income inequality and LBW was reduced in all time lagged models, except the five year time lag. The relation was statistically significant only in the five year lagged models, where the association with income inequality was similar to that of the contemporaneous model.

Table 3 presents results of the pooled, cross sectional, time series regression model examining predictors of state level infant mortality rates. In bivariate analyses (model 1), contemporaneous measures of income inequality were significantly associated with higher state levels of infant mortality $(\mathrm{p}<0.0001)$. In analyses controlling for primary care (model 2), primary care was significantly associated with lower infant mortality $(p<0.0001)$. Income inequality remained statistically significant, but its magnitude decreased from that in the bivariate analysis. In the full analyses (model 3), primary care decreased in magnitude by more than one half but remained a significant predictor of lower rates of infant mortality $(\mathrm{p}<0.0001)$. The coefficient for income inequality decreased to about one eighteenth of its value in the bivariate model, and was no longer significant $(p>0.05)$. The percentage of the state's population that is African-American was positively associated with infant mortality $(p<0.0001)$, but the percentage urban and the percentage with at least a high school education were not statistically significant predictors.

In the case of infant mortality the time lagged models paint a different picture than do the contemporaneous ones. The magnitude of the primary care regression coefficient increased with each lagged year, peaked at the three year lag, and gradually declined to a value below that of the contemporaneous model. Primary care was statistically significant each year. In the model controlling for primary care, the magnitude of the income inequality regression coefficient fluctuates over time, but was statistically significant in each lagged period. With the addition of social variables, (model 3) the magnitude of the income inequality coefficient was greatly reduced, and was not statistically significant. The association with race/ethnicity and urban residence were similar in magnitude and statistical significance in both contemporaneous and time lagged models. Unemployment and education covariates only became significant $(\mathrm{p}<0.05)$ after a three year lag. No significant interaction was detected between primary care and income inequality.

\section{DISCUSSION}

This study provides additional evidence of a negative ecological level association between primary care and infant mortality and LBW-even after controlling for income inequality and sociodemographic covariates. In multivariate models, an increase of one primary care doctor per 10000 population was associated, on average, with a $2.5 \%$ reduction in infant mortality and a $3.2 \%$ reduction in LBW. Results of time lagged models show that in addition to a contemporaneous relation, primary care also had an association with birth outcomes over time. All else being equal, we would expect primary care to be associated with reduced infant mortality, primarily through better maternal health and lower post-neonatal mortality. The data observed here support this hypothesis.

Infant mortality in the United States has declined more than $45 \%$ since $1980 .^{36}$ Postulated reasons for this decline include the widespread adoption of technologies that have prevented fetal mortality, resulting in increased LBW but reducing neonatal mortality that ultimately lowered overall

\section{Key points}

- In US states, contemporaneous and time lagged measures of primary care were associated with lower infant mortality and fewer low birthweight births.

- In multivariate, pooled, cross sectional, time series analyses, an increase of one primary care doctor per 10000 population was associated with a $2.5 \%$ reduction in infant mortality and a $3.2 \%$ reduction in low birth weight

- Income inequality was positively associated with low birth weight and infant mortality, but its effect on infant mortality disappeared with the addition of primary care and other covariates. 
IMR. ${ }^{37}$ Reductions in sudden infant death syndrome deaths through parental education efforts also seem to have contributed to lower IMR beginning in the 1990s. ${ }^{38}$ The bulk of remaining infant mortality appears among extremely premature and very LBW babies-both of which are increasingly concentrated within groups of low socioeconomic position. ${ }^{37}$ Despite this decline, absolute levels of infant mortality are higher in the United States than in most other OECD countries, and disparities between ethnic and socioeconomic groups in the United States are growing larger. ${ }^{36}$

There are several posited causes for the higher than expected rates of infant mortality in the United States, but one of the most relevant to this discussion is poor access to appropriate health care. The United States is the only industrialised country that does not provide financial coverage for health care to all its citizens. Although other countries with universal health systems, such as the United Kingdom, also have significant disparities in infant mortality among different population groups, absolute levels are higher in the United States than in similar countries. Despite increased access to prenatal care for most women in the United States, there has not been a concomitant decrease in levels of LBW. ${ }^{39}$ Nevertheless, international studies have shown that health systems providing universal access to continuous and comprehensive primary care services throughout the lifespan can result in reduced overall rates of mortality for infants as well as adults. ${ }^{40}$

However, when examining the determinants of infant mortality it is important to independently assess its two components: neonatal (deaths within the first 28 days) and post-neonatal mortality (deaths after 28 days and before 1 year). The principal causes of postneonatal deaths in the US have been infant infections, sudden infant death syndrome, unintentional injuries, and factors associated with poverty. Neonatal mortality has been determined primarily by processes associated with birth, including congenital abnormalities, difficulties during delivery, and LBW. ${ }^{37}$ Both have declined precipitously in the United States; about two thirds of infant mortality is now attributable to neonatal mortality associated with low and very LBW, while postneonatal mortality is responsible for the remaining third. ${ }^{36}$

There are several mechanisms through which primary care may influence birth outcomes. Firstly, primary care has been associated in the US and in international studies with lower post-neonatal mortality rates. ${ }^{41}$ The main mechanisms for this association seems to be a combination of improved maternal health and better management of conditions affecting infants in the post-neonatal period, including identification and treatment of infections, teaching mothers about safe infant sleeping positions (thus reducing the potential for sudden infant death syndrome), and reduction of potential injuries through increased use of car safety seats and provision of household safety information. ${ }^{3842}$ Of particular note is the effectiveness of "back to sleep" campaigns in lowering infant mortality attributable to injuries. Although not all such health promotion efforts take place in primary care, Willinger et $a l^{38}$ report that in multivariate models, physician recommendation to place infants in a supine position for sleep was the strongest predictor of infant sleep position (OR 2.38-4.76). Additional risk factors for sudden infant death syndrome that might be influenced (though not exclusively so) by primary care include LBW, prenatal smoke exposure, and late initiation of prenatal care. ${ }^{43}$

Secondly, primary care is responsible for dealing with a range of maternal health problems that are associated with higher rates of infant mortality, including smoking, alcoholism, drug use, poor weight gain during pregnancy, sexually transmitted diseases, and poor nutrition. There is evidence that interactions among these risk factors greatly increase the risk of LBW..$^{44}$ Indeed, there is growing awareness that "when care for women is viewed as an integrated continuum approach to health, rather than as a series of episodic events, higher levels of women's wellness will be achieved. This approach is likely to result in healthier women, pregnancies, and offspring" ${ }^{45}$ The time lagged associations of primary care on infant mortality are consistent with a longer term association through a mechanism such as improved maternal health. Moreover, our study found an association between primary care and LBW, thus supporting the link between primary care, maternal health, and birth outcomes. In international comparisons, better primary care is also associated with less LBW. ${ }^{46}$

Based on the results of this study and previous research it seems probable that primary care may act both through specific mechanisms directed towards infants (education efforts to promote proper infant sleeping position and use of child safety seats) and through a less direct route; primary's care's continuous, comprehensive, person focused care over the lifespan of women. ${ }^{47}$ It is this continuous and comprehensive care that we hypothesise might counteract some of the negative health burden associated with living in an area with high social inequalities, thus interacting with accumulated disadvantage and its implications for health.

Regarding a link between birth outcomes and social inequalities, there is evidence that work related stress and physical exertion on the job may both lead to pre-term deliveries. ${ }^{48}{ }^{49}$ Similar types of stress have been hypothesised to result from unfavourable social comparisons caused by income and other social disparities within communities. ${ }^{7}$ Thus, it is possible that social inequalities may contribute to infant mortality through both material (poverty, differential access to services) and psychosocial (stress) pathways. The evidence presented here suggests that primary care may act to mitigate at least some of the negative impact of social inequalities on health by lowering the chances of LBW and improving the odds of infant survival during the first year of life-despite the existence of social inequalities.

As a sensitivity test, we tested the interaction between primary care and income inequality in the full multivariate models for both health outcomes. The results (not shown) indicate that the association of primary care with infant mortality does vary with increasing levels of income inequality. That is, all else being equal, an increase in primary care resources would have the largest impact in an area with higher rather than lower levels of social inequalities. This is consistent with our prior research showing that the potential improvement in health attributable to increased primary care varied with a metropolitan area's level of income inequality. Controlling for other factors, people living in areas with highly unequal income distributions were 33\% more likely to report poor or fair health if they lived in an area with lower rather than higher primary care resources. ${ }^{19}$

Some authors have posited that the observed relation between income inequalities and health is largely explained by differences between health outcomes among AfricanAmerican and white populations in the United States. ${ }^{50}$ There

\section{Policy implications}

This study adds to mounting evidence that increasing primary care services represents one strategy to mitigate some of the negative impact of social inequalities on population health. 
is, in fact, considerable evidence of a gap in infant mortality between babies born to African-American compared with white mothers. ${ }^{36}$ Among the highest socioeconomic groups, the infant mortality rate for African-Americans was more than twice that of the white population, but this gap narrows significantly when comparing the poorest white and AfricanAmerican mothers. ${ }^{51}{ }^{52}$ There are several explanations for this finding. Firstly, African-American women are less likely than white women to use primary care and prenatal care, even among populations with similar socioeconomic and health plan characteristics..$^{53}$ Secondly, even when they do receive it, African-American and other women of colour are more likely to receive poorer quality care than that received by their white counterparts. ${ }^{54} 55$ Thirdly, our analyses show that the percentage of the population in each state that is AfricanAmerican is a powerful, statistically significant predictor of higher infant mortality and LBW. However, when we controlled for the percentage of population identified as African-American, average levels of education, unemployment rates, and urbanisation, income inequality continued to exert a negative impact on LBW. Some studies have postulated that this additional gap between white and African-American birth outcomes may be attributable to underlying social disadvantage. ${ }^{56} 57$ If we view wide gaps in income distribution as an indicator of social inequality, then this observation is consistent with our results that show a significant impact of income inequality on birth outcomes, even while controlling for other sociodemographic characteristics of the population.

In interpreting the results of this study, several limitations require consideration. Because the study design is ecological, we cannot say that people who suffer most from ill health because of income inequality would gain the most from improved primary care. However, conditions leading to poor maternal health such as smoking and poor nutritional status, have also been shown to be more prevalent in areas with higher income inequality. ${ }^{58} 59$ Primary care may be able to ameliorate some of the ultimate consequences of income inequalities at the population level by contributing to lower aggregate levels of risk factors before pregnancy, by improving access to prenatal care and early diagnosis activities, and developing systems to coordinate care. ${ }^{60}{ }^{61}$ It is also possible that primary care is serving as an indicator of another latent state level variable. However, given the consistency of the relation in our previous studies that used different health outcomes (for example, self rated health, all cause mortality, stroke mortality), datasets, and units of analysis, this seems unlikely.

The finding of a relation between primary care physicians and lower mortality rates does not necessarily imply that the mere presence of more primary care physicians assures either that more individuals in the population are exposed to primary care or that the delivery of primary care will produce better health outcomes at the individual level. These hypotheses must be tested using individual level data.

In addition, it is possible that not all potential determinants of health outcomes were able to be modelled in this study. For example, the percentage of births to teens and the percentage of births to unwed mothers were not included as covariates. However, because of the fact that these covariates are correlated with other health determinants already captured in our model (level of education and the percentage of the population that is African-American), their additional explanatory power is probably limited.

One advantage to performing a longitudinal analysis is that we were able to control for (but not estimate the value of) unmeasured ecological level confounders. Time invariant state level characteristics (such as stable state level policy factors, persistent differences in infrastructure and resources, histories of segregation and discrimination, and slowly changing macro-level social relations) were captured and controlled for in our analysis through the inclusion of state level fixed effects in the statistical model. ${ }^{62}$ Regression diagnostics confirmed that removing potentially outlying points did not affect results.

As a final sensitivity test, results were analysed for geographical trends within the major US regions as defined in by the Census Bureau (that is, Northeast, South, Midwest, and West). The Southern region was used as the reference group. For both outcomes, regional variables (West and Midwest) were found to be statistically significant and their inclusion in the full model with all other covariates resulted in the Gini measure losing statistical significance. However, the association between primary care and health outcomes was not changed by the presence of the regional variable. This test suggests that at least part of the negative association between income inequality and birth outcomes might be attributable to variation at the regional rather than the state level.

Finally, primary care physician availability may be an inadequate proxy for receipt of good primary care. Ultimately, we would like better information on the structural characteristics and practice features of primary care. Unfortunately, there are no data that make it possible to adequately characterise receipt of good primary care (as distinguished from receipt of ambulatory care services, which also include specialty care) at the state level. Other healthcare providers, such as osteopathic doctors, nurse practitioners, and physician assistants also practice primary care but were not captured. For these reasons, it is probable that our analysis underestimates the overall contribution of primary care.

\section{Authors' affiliations}

L Shi, B Starfield, J Xu, The Johns Hopkins Bloomberg School of Public Health, Baltimore, USA

J Macinko, New York University Steinhardt School of Education, New York, USA

J Regan, R Politzer, J Wulu, Bureau for Primary Care, Health Resources and Services Administration, US Department of Health and Human Services, USA

Funding: this study was funded by the Johns Hopkins Primary Care Policy Center.

Conflicts of interest: none declared.

\section{REFERENCES}

1 Kennedy B, Kawachi I, Prothrow-Stith D. Income distribution and mortality: cross sectional ecological study of the Robin Hood index in the United States. BMJ 1996;312:1004-7

2 Kaplan G, Pamuk E, Lynch J, et al. Inequality in income and mortality in the US: analysis of mortality and potential pathways. BMJ 1996:312:999-1003.

3 Kawachi I, Kennedy B, Lochner K, et al. Social capital, income inequality, and mortality. Am J Public Health 1997;87:1491-8.

4 Lochner K, Pamuk E, Makuc D, et al. State-level income inequality and individual mortality risk: a prospective, multilevel study. Am J Public Health 2001;91:385-91.

5 Blakely T, Lochner K, Kawachi I. Metropolitan area income inequality and selfrated health-a multi-level study. Soc Sci Med 2002;54:65-77.

6 Wilkinson R. Income inequality, social cohesion, and health: dlarifying the theory-a reply to Muntaner and Lynch. Int J Health Serv 1999;29:525-43.

7 Marmot M, Wilkinson R. Psychosocial and material pathways in the relation between income and health: a response to Lynch et al. BMJ 2001;322:1233-6

8 Everson S, Goldberg D, Kaplan G, et al. Hopelessness and risk of mortality and incidence of myocardial infarction and cancer. Psychosomatic Med 1996;58:113-21.

9 Miller TQ, Guilarro ML, Hallet AJ, et al. A meta-analytic review of research on hostility and physical health. Psychol Bull 1996;1 19:322-48.

10 Kawachi I, Kennedy B, Glass R. Social capital and self-rated health: a contextual analysis. Am J Public Health 1998;89:1 187-93.

11 Kawachi I, Kennedy BP, Lochner K, et al. Social capital, income inequality, and mortality. Am J Public Health 1997;87:1491-8.

12 Lynch J, Kaplan G. Understanding how inequality in the distribution of income affects health. J Health Psychol 1997;2:297-314. 
13 Lynch J. Income inequality and health: expanding the debate. Soc Sci Med 2000;51:1001-5

14 Judge K, Paterson I. Poverty, income inequality and health. Auckland: New Zealand Treasury, 2002

15 Muntaner C, Lynch J, Oates GL. The social class determinants of income inequality and social cohesion. Int J Health Serv 1999;29:699-732.

16 Navarro V, Shi L. The political context of social inequalities and health. Soc Sci Med 2001;52:481-91.

17 Shi L, Starfield B, Kennedy B, et al. Income inequality, primary care, and health indicators. J Fam Practice 1999;48:275-84.

18 Shi L, Starfield B. The association of primary care physician supply and income inequality on mortality among blacks and whites in US metropolitan areas. Am J Public Health 2001;91:1246-50.

19 Shi L, Starfield B. Primary care, income inequalities, and self-rated health in the United States: a mixed-level analysis. Int J Health Serv 2000;30:541-55.

20 Shi L, Starfield B, Politzer R, et al. Primary care, self-rated health, and reduction in social disparities in health. Health Serv Res 2002;37:529-50.

21 US Department of Health and Human Services Bureau of Primary Care. Moving toward $100 \%$ access and 0 health disparities. http://bphc.hrsa.gov/ campaign (accessed Dec 2002).

22 US Department of Health and Human Services, National Center for Health Statistics (NCHS). Compressed Mortality Files. Washington, DC: US Department of Health and Human Services, 2000.

23 US Department of Health and Human Services, National Center for Health Statistics. Health, United States. Washington, DC: US Department of Health and Human Services, 1985-1996.

24 US Department of Health and Human Services, Centers for Disease Control and Prevention. Health status indicators: definitions and national data. Statistical Notes 1992;1:1-8.

25 American Medical Association. Physician characteristics and distribution in the United States. Chicago, IL: American Medical Association, 1985-1995.

26 Kawachi I, Kennedy BP. The relationship of income inequality to mortality: does the choice of indicator matter? Soc Sci Med 1997:45:1121-7.

27 US Census Bureau. Statistical abstracts of the United States. Washington, DC: US Census Bureau, 1985-1995.

28 Blakely T, Kawachi I. What is the difference between controlling for mean versus median income in analyses of income inequality? J Epidemiol Community Health 2001;55:352-3.

29 Susser M. The logic in ecological, I: the logic of analysis. Am J Public Health 1994;84:825-9.

30 Schwartz $\mathbf{S}$. The fallacy of the ecological fallacy: the potential misuse of a concept and the consequences. Am J Public Health 1994;84:819-24.

31 Hadley J. More medical care, better health? Washington, DC: The Urban Institute Press, 1982.

32 SAS/STAT. User's guide. Cary, NC: SAS Institute, 1999.

33 Littell RC, Pendergast J, Natarajan R. Modelling covariance structure in the analysis of repeated measures data. Stat Med 2000;19:1793-819.

34 Hsiao C. Analysis of panel data. Cambridge: Cambridge University Press, 1986.

35 Long S. Regression models for categorical and limited dependent variables. Thousand Oaks, CA: Sage, 1997.

36 US Centers for Disease Control and Prevention. Infant mortality and low birth weight among black and white infants-United States, 1980-2000. MMWR 2002;51:589-92.

37 Gortmaker S, Wise P. The first injustice: socioeconomic disparities, health services technology, and infant mortality. Annual Review of Sociology 1997;23:147-70

38 Willinger $\mathrm{M}$, Hoffman $\mathrm{HJ}, \mathrm{Wu}$ K, et al. Factors associated with the transition to non-prone sleep positions of infants in the United States: national infant sleep position study. JAMA 1998;280:329-35.

39 Korenbrot C, Moss N. Preconception, prenatal, perinatal, and postnatal influences on health. In: Smedley B, Syme S, eds. Promoting health: intervention strategies from social and behavioral research. Washington, DC: National Academy Press, 2000.

40 Macinko J, Starfield B, Shi L. The contribution of primary care systems to health outcomes within OECD countries, 1970-1998. Health Serv Res 2003:38:819-53.

41 Starfield B. Postneonatal mortality. Annu Rev Public Health 1985;6:21-40.

42 Papacek E, Collins J, Schulte N, et al. Differing postneonatal mortality rates of African-American and white infants in Chicago: an ecologic study. Matern Child Health J 2002;2:99-105.

43 Paris C, Remler R, Daling J. Risk factors for sudden infant death syndrome: changes associated with sleep position recommendations. J Pediatr 2001;139:771-7.

44 Bakketeig L, Jacobsen G, Hoffman $\mathrm{H}$, et al. Pre-pregnancy risk factors of small for gestational age birth among parous women in Scandinavia. Acta Obstet Gynecol Scand 1993;72:273-9.

45 Moos MK. Preconceptional wellness as a routine objective for women's health care: an integrative strategy J Obstet Gynecol Neonatal Nurs 2003;32:550-6

46 Starfield B, Shi L. Policy relevant determinants of health: an international perspective. Health Policy 2002;60:201-18.

47 Starfield B. Primary care: balancing health needs, services and technology. New York: Oxford University Press, 1998.

48 Homer C, James S, Siegel E. Work-related psychosocial stress and risk of preterm low birthweight delivery. Am J Public Health 1990;80:173-7.

49 Homer C, Berresford S, James S, et al. Work-related physical exertion and risk of preterm low birthweight delivery. Paediatr Perinat Epidemiol 1990:4:161-74.

50 Deaton AS. Health, inequality, and economic development. Geneva: WHO Commission on Macroeconomics and Health, 2001.

51 Starfield B, Shapiro S, Weiss J, et al. Race, family income, and low birth weight. Am J Epidemiol 1991;134:1167-74.

52 Schoendorf K, Hogue C, Kleinman J, et al. Mortality among infants of black as compared to white college-educated parents. N Engl J Med 1992;326:1522-6.

53 Hoffmann CBR, Tyson JE. Emergency room visits despite the availability of primary care: a study of high risk inner city infants. Am J Med Sci 1997;313:99-103.

54 Shi L. Experience of primary care by racial and ethnic groups in the United States. Med Care 1999;37:1068-77.

55 Hansell $M$. Sociodemographic factors and the quality of prenatal care. Am J Public Health 1991;81:1023-8.

56 Rowley D. Framing the debate: can prenatal care help to reduce the blackwhite disparity in infant mortality? J Am Med Women Assoc 1995; 50:187-93

57 Rowley D. Beyond the medical model: research on social factors and preterm delivery. Prenat Neonat Med 1998;3:170-2.

58 Diez-Roux AV, Link BG, Northridge ME. A multilevel analysis of income inequality and cardiovascular disease risk factors. Soc Sci Med 2000;50:673-87.

59 Kahn HS, Tatham LM, Pamuk ER, et al. Are geographic regions with high income inequality associated with risk of abdominal weight gain? Soc Sci Med 1998;47:1-6.

60 Goldstein LB, Farmer A, Matchar DB. Primary care physician-reported secondary and tertiary stroke prevention practices. A comparison between the United States and the United Kingdom. Stroke 1997;28:746-51.

61 Goldstein LB, Bian J, Samsa GP, et al. New transient ischemic attack and stroke: outpatient management by primary care physicians. Arch Intern Med 2000;60:2941-6.

62 Hsiao C. Analysis of panel data. Cambridge: Cambridge University Press, 1986 